\title{
Penerapan Teknologi Otomatisasi dalam Pertanian Agrotech Farm System
}

\author{
Nurliana Nasution*1, Sri Utami Lestari², Mhd Arief Hasan ${ }^{3}$ \\ 1,3Program Studi Teknik Informatika, Fakultas Ilmu Komputer, Universitas Lancang Kuning \\ 2Program Studi Agribisnis, Fakultas Pertanian, Universitas Lancang Kuning \\ *e-mail: nurliananst@unilak.ac.id ${ }^{1}$, sriutami@unilak.ac.id²,m.arif@unilak.ac.id ${ }^{3}$
}

\begin{abstract}
The Katon Jaya Pekanbaru Farmers Group started the success of their respective lands which were managed together with members of the Katon Jaya Pekanbaru Farmers Group. Along with the trust of the Pekanbaru City Government, Mr. Awaldi Hasibuan and the Katon Jaya farmer group were given the trust to manage 20 hectares of agro-tourism land. This creates new problems in the land of the Katon Jaya farmer group which has become neglected in managing the land belonging to the farmer group. Their land has become neglected, neglected because they have to focus on the main land in the Agrotourism Village of Pekanbaru City. The land of the farmer group is experiencing aridity and is overgrown with grass and becomes unproductive land again. In terms of land, this farmer group was often used as a mini laboratory for visits from several parties who wanted to learn about plant cultivation. In this land, they often provide education and learning about good plant cultivation management techniques. So that people become aware of the importance of agricultural management, especially in urban areas. Priority issues that are mutually agreed upon between partners and universities are resolved jointly. These stages are described as follows. Revive the agricultural land of the Katon Jaya Farmers Group by providing assistance in the form of agricultural food products (Vegetables). Providing assistance solutions in the form of installing Agrotech Farm System Equipment at the Katon Jaya Farmer Group. Provide Training on the Use of Agrotech Farm System to Katon Jaya Farmer Groups to make their land Technology-based Agricultural Education. The outputs of this research are Video Documentation Activities (Youtube), Media Publications, Journals, Enhancement of Partner Empowerment, and Textbooks..
\end{abstract}

Keywords: Farmer Group, Agro Tech, Smart Farming, Agriculture, Modern

\begin{abstract}
Abstrak
Kelompok Tani Katon Jaya Pekanbaru mengawali kesuksesan dari lahan milik mereka masingmasing yang dikelola bersama-sama anggota Kelompok Tani Katon Jaya Pekanbaru. Seiring dengan kepercayaan pihak Pemerintah Kota Pekanbaru, maka bapak Awaldi Hasibuan dan kelompok Tani Katon Jaya diberikan kepercayaan untuk mengelola lahan Agrowisata sebanyak 20 Hektar. Hal ini menimbulkan permasalan baru di lahan kelompok tani Katon Jaya yang menjadi terbengkalai dalam mengelola lahan milik kelompok tani tersebut. Lahan mereka menjadi terbengkalai, tidak terurus karena harus fokus ke lahan utama di Kelurahan Agrowisata Kota Pekanbaru. Lahan kelompok tani, ada mmengalami kegersanggan dan ditumbuhi rerumputan serta menjadi lahan tidak produktif kembali. Pada hal lahan kelompok tani ini dulunya sering sekali dijadikan sebagai laboratorium mini untuk kunjungan-kunjungan dari beberapa pihak yang ingin belajar budi daya tanaman. Di lahan ini sering memberikan edukasi dan pembelajaran mengenai teknik pengelolaan budi daya tanaman yang baik. Sehingga masyarakat menjadi sadar akan pentingnya pengelolaan pertanian terutama di daerah perkotaan. Permasalahan prioritas yang menjadi kesepakatan bersama antara mitra dan perguruan tinggi diselesaikan secara bersama. Tahapan-tahapan tersebut diurakan sebagai berikut. Menghidupkan lahan pertanian Kelompok Tani Katon Jaya tersebut dengan memberikan bantuan berupa produk pertanian pangan (Sayur-Mayur). Memberikan solusi bantuan berupa pemasangan Alat Agrotech Farm System pada Kelompok Tani Katon Jaya. Memberikan Pelatihan Penggunaan Agrotech Farm System Kepada Kelompok Tani Katon jaya untuk menjadikan lahan mereka Edukasi Pertanian berbasis Teknologi. Luaran Penelitian ini berupa Video Dukumentasi Kegiatan (Youtube), Publikasi Media, Jurnal, Peingkatan Pemberdayaan Mitra, dan Buku Ajar.
\end{abstract}

Kata kunci: Kelompok Tani, Agro Tech, Smart Farming, Pertanian, Modern

\section{PENDAHULUAN}

Kota Pekanbaru merupakan kota terbesar di Provinsi Riau, Indonesia, memiliki luas $632,26 \mathrm{Km} 2$ yang terdiri dari 12 Kecamatan berdasarkan peraturan daerah nomor 4 tahun 2003, dengan jumlah kelurahan sebanyak 83 kelurahan, dimana kecamatan terluas adalah Tenayan 
Raya seluas 171,27 Km2, kemudian Rumbai Pesisir seluas 157,33 Km2 dan Rumbai 128,85 Km2, untuk luas wilayah per kecamatan. Kawasan yang relatif tinggi dan berbukit terutama dibagian utara kota, khususnya di Kecamatan Rumbai dan Rumbai Pesisir dengan ketinggian rata- rata sekitar 50 meter di atas permukaan laut. (Sumber: BPS Pekanbaru).

Kota Pekanbaru merupakan salah satu sentra ekonomi terbesar di Pulau Sumatra, dan termasuk sebagai kota dengan pertumbuhan, migrasi dan urbanisasi yang tertinggi. Hal ini mengakibatkan areal pertanian semakin sempit dan sedikit. Sesuai dengan visi Kota Pekanbaru yaitu: Terwujudnya Pekanbaru Sebagai Smart City Madani (Taufiq, Sunanto, and Rizki 2020). Untuk pencapaian misi pembangunan jangka menengah Kota Pekanbaru salah satu misi dari Kota Pekanbaru adalah Mewujudkan Tata Kelola Kota Cerdas dan Penyediaan Infrastruktus yang Baik.

Kelurahan Agrowisata merupakan salah satu dari Kecamatan Rumbai yang bertemakan pertanian dan di resmikan oleh Walikota Pekanbaru pada tanggal 22 November 2019. Kelurahan Agrowisata yang posisinya sangat strategis tepatnya di kawasan perencanaan jalan lingkar 70 yang menghubungkan dengan jalur tol Pekanbaru-Dumai dan Pekanbaru-Sumbar. Kawasan agrowisata ini memiliki konsep gabungan antara edukasi pendidikan, ekonomi dan pariwisata. Sesuai dengan keinginan Pemko Pekanbaru dalam mengelola setiap daerah menjadi salah satu daerah andalan dan pembangunan pusat pariwisata dan juga Kelurahan Agrowisata ini diharapkan bisa menjadi magnet wisatawan nasional dan asing (Agrowisata and Kota 2021). Ada 20 hektar lahan pertanian yang sudah disiapkan sebagai penunjang wisata agro di Kelurahan Agrowisata tersebut. Baru lahan 20 hektar pemanfaatannya yang digunakan untuk lahan agrowisata. Bermacam-macam tanaman buah-buah dan sayuran yang ditanam, seperti: melon, pepaya, cabe, ubi, serta komoditi lainnya (Siswati, Zargustin, and Nizar 2020). Untuk pengembangan dari Kelurahan Agrowisata, sangat membutuhkan dukungan dari berbagai pihak. Tidak hanya Pemerintah saja, bahkan sektor swasta dan Universitas diharapkan juga agar mau untuk berinvestasi demi kemajuan pariwisata Kota Pekanbaru.



Gambar 1. Walikota Pekanbaru Bersama Ketua Kelompok Tani Katon Jaya Kelurahan Agrowisata di Lahan 20 Hektare Kelurahan Agowisata

Terwujudnya lahan Agrowisata 20 Hektar di Kelurahan Agrowisata ini yang menjadi inisiator dari Bapak Awaldi Hasibuan sebagai ketua Kelompok Tani Nelayan Andalan (KTNA) Kota Pekanbaru. Bapak Awaldi Hasibuan juga sebagai Ketua Kelompok Tani Katon Jaya Pekanbaru. Bersama anggota kelompoknya Bapak Awaldi Hasibuan sering memberikan penyuluhan kepada petani lain mengenai mekanisme pertanian di Kota Pekanbaru. Bersama kelompok taninya pernah meraih prestasi tentang Penyuluh Swadaya Pertanian Terbaik pada tahun 2015. 



Gambar 2. Menjadi Penyuluh Swadaya Nasional Terbaik Tahun 2015

Bapak Awaldi Hasibuan bersama Kelompok Tani Katon Jaya Pekanbaru mengawali kesuksesan dari lahan milik mereka masing-masing yang dikelola bersama-sama anggota Kelompok Tani Katon Jaya Pekanbaru. Kelompok Tani Katon Jaya merupakan salah satu kelompok tani yang paling berperan penting dalam terciptanya Kelurahan Agrowisata Kota Pekanbaru. Kelurahan Agrowisata yang dibuat ini sebagai penopang pertanian perkotaan di Kota Pekanbaru. Setiap harinya kelompok tani ini bekerja di lahan agrowisata dan kelompok tani lainnya kewalahan untuk mengelola lahan mereka sendiri yang berada tidak jauh dari destinasi agrowisata tersebut.
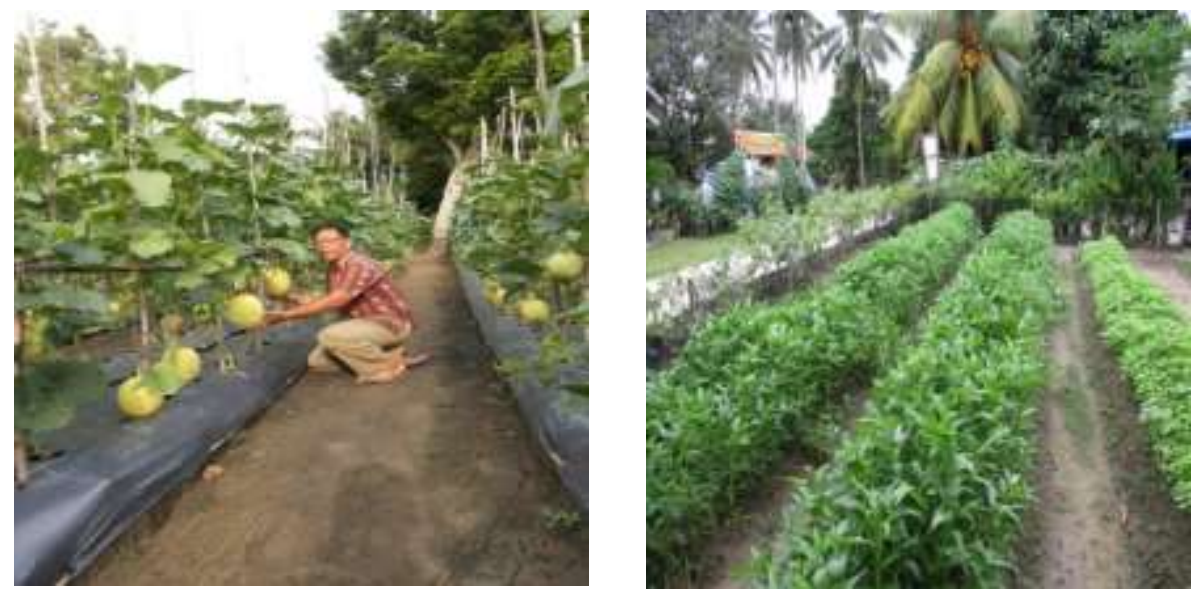

Gambar 3. Lahan Pertanian yang dikelola oleh Kelompok Tani Katon Jaya Sebelum Mengelola Lahan Agrowisata 20 Hektar

Pada Gambar 3 diatas terlihat kondisi dimana Kelompok Tani Katon Jaya memulai usaha mereka. Sehingga bisa menjadi sukses, dan dipercaya oleh bapak Walikota Pekanbaru untuk mengelola lahan yang lebih luas lagi.

Seiring dengan kepercayaan pihak Pemerintah Kota Pekanbaru, maka bapak Awaldi Hasibuan dan kelompok Tani Katon Jaya mengelola diberikan kepercayaan untuk mengelola lahan Agrowisata sebanyak 20 Hektar. Hal ini menimbulkan permasalan baru di lahan kelompok tani Katon Jaya yang menjadi terbengkalai dalam mengelola lahan milik kelompok tani tersebut. Lahan mereka menjadi terbeng kalai, tidak terurus dikarenakan harus fokus ke lahan Utama di Kelurahan Agrowisata Kota Pekanbaru. Lahan kelompok tani yang ada kembali menjadi gersang dan ditumbuhi rerumputan serta menjadi lahan tidak produktif kembali. Pada hal lahan kelompok tani dulunya sering sekali dijadikan sebagai laboratorium mini untuk kunjungan-kunjungan dari beberapa pihak yang ingin belajar budi daya tanaman. Di lahan ini sering memberikan edukasi dan pembelajaran mengenai teknik pengelolaan budi daya tanaman yang baik. Masyarakat dan 
instansi terkait berkunjung ke lahan ini untuk dapat melihat secara langsung mengenai hasil budidaya tanaman. Sehingga masyarakat menjadi sadar akan pentingnya pengelolaan pertanian terutama di daerah perkotaan. Pada Gambar 4 menjelaskan beberapa pelatihan dan edukasi yang dilakukan Kelompok Tani Katon Jaya Kepada Masyarakat mengenai budi daya tanaman di lahan milik mereka sendiri.
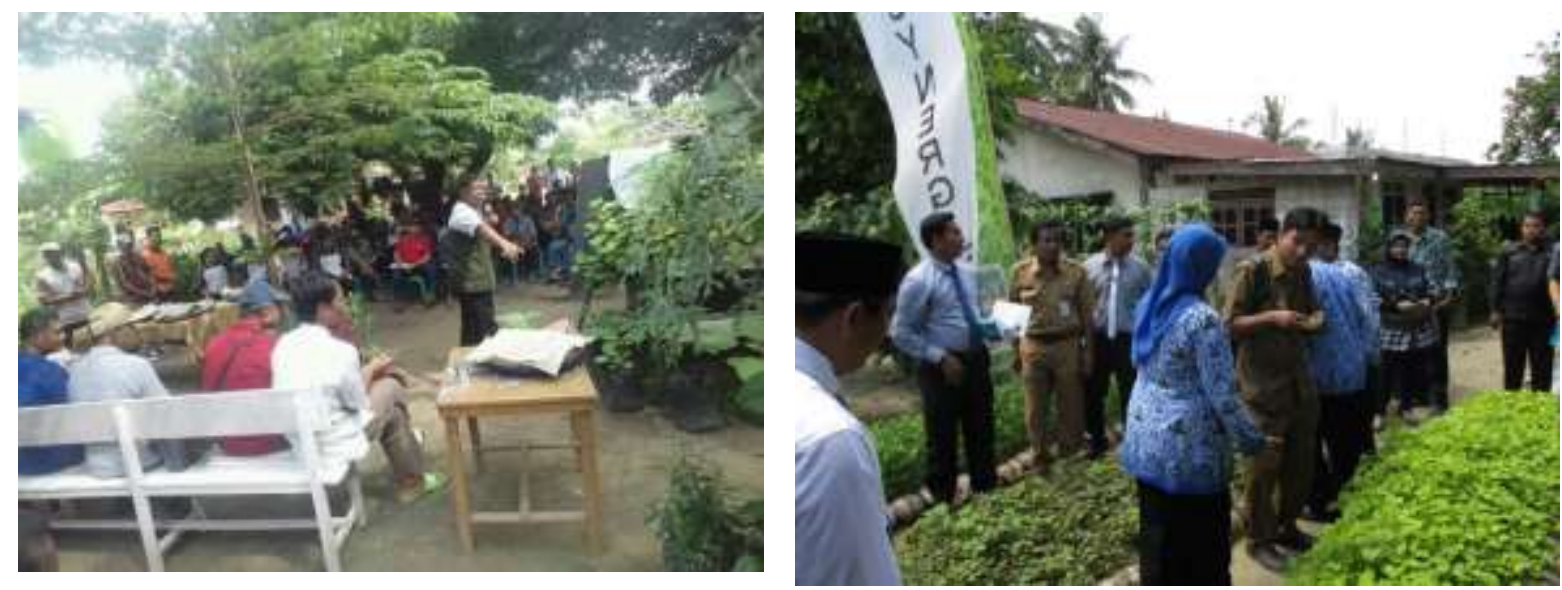

Gambar 4. Beberapa Kunjungan dan Edukasi Ke Lahan Kelompok Tani Katon Jaya

Lahan ini terbiarkan terbengkalai padahal areal ini sering menjadi kunjungan-kunjungan baik dari Kota Pekanbaru maupun dari luar Provinsi Riau. Saat ini kendala utama yang mereka hadapi dalam pengelolaan lahan sendiri adalah sulitnya mengenai manajemen waktu budidaya tanaman. Kelompok tani tidak dapat lagi menemukan waktu yang ideal untuk mengelola lahan mereka terutama untuk irigasi dan pemupukan. Hal ini karena waktu kelompok tani sudah tersibukkan di lahan Agrowisata yang 20 hektar tersebut. Untuk itu perlu ada upaya solusi dari lahan yang terbengkalai agar bisa digunakan kembali, mengingat jaringan telekomunikasi berupa fiber optic sudah masuk ke wilayah tersebut. Jaringan ini dapat dimanfaatkan sebagai jalur komunikasi untuk menghidupkan lahan melalui mekanisasi otomatisasi dalam pengairan dan pemupukan. Sekaligus laboratorium pertanian dasar yang mereka telah bangun sebelumnya bisa agar kembali menjadi normal. Bahkan dengan adanya upaya otomatisasi ini akan menjadi semakin meningkatkan kualitas laboratorium kelompok tani itu sendiri. Adanya teknologi otomatisasi pertanian ini yang seiring dengan visi misi dari Kota Pekanbaru menjadi Kota Smart City Madani. Untuk indikator tersebut dapat dilihat dari penggunaan Teknologi Otomatisasi dalam pertanian.

Berdasarkan uraian analisis situasi sebelumnya, ada beberapa permasalahan dari mitra yang peneliti uraikan sebagai berikut.

a. Kesulitan dari Kelompok Tani Katon Jaya dalam mengelola lahan milik mereka sendiri, karenakan kelompok tani tersebut harus banyak meluangkan waktu di lahan Agrowisata yang luasnya 20 Hektar milik Kota Pekanbaru dan tanggung jawabnya dibebankan kepada Kelompok Tani Katon Jaya.

b. Lahan milik Kelompok Tani Katon Jaya, sering menjadi kunjungan dari beberapa pihak, baik instansi, Pemerintahan, Pendidikan, Masyarakat dan lainnya yang ingin belajar budi daya tanaman di Kelurahan Agrowisata. Namun karena lahan tersebut saat ini terbengkalai, maka perlu adanya peningkatan kualitas lahan untuk Kelompok Tani Katon Jaya.

c. Lahan Kelompok Tani Katon Jaya yang dulunya menjadi Laboratorium pembelajaran untuk budi daya tanaman dengan cara manual, maka dengan adanya teknologi komunikasi yang masuk wilayah Kelurahan Agrowisata tersebut, sebaiknya menggunakan teknologi komunikasi yang ada agar dapat meningkatkan kualitas labor pembelajaran yang dulunya masih manual menjadi menggunakan teknologi otomatisasi. 
d. Perlu adanya upaya untuk menjawab tantangan dari visi dan misi Kota Pekanbaru untuk menjadikan Kota Smart City Madani, menggunakan indikator Smart Teknologi didalam Pertanian.

\section{METODE}

a. Khalayak Sasaran

Khalayak sasaran pengabdian masyarakat ini tentu saja adalah Anggota Kelompok Tani Katon Jaya Kelurahan Agrowisata Kota Pekanbaru. Pelaksanaan pengabdian ini juga melibatkan beberapa mahasiswa yakni mahasiswa Teknik Informatika (3 Orang) dan Mahasiswa Pertanian (3 Orang) dari Universitas Lancang Kuning. Ditambah beberapa teknisi lapangan yang membantu dalam operasional pengelolaan lahan pertanian dan Teknisi mekanisasi Alat Agrotech Farm System. Pembagian tugas di lakukan agar definisi tugas terukur dengan jelas. Step by step pengerjaan akan dibuatkan sebagai panduan mereka untuk pengerjaan lahan pertanian dari Kelompok Tani Katon Jaya sekaligus pemasangan alat Agrotech Farm System. Mereka bertugas sesuai dengan fungsi mereka masing-masing untuk mendampingi kelompok Tani Katon Jaya. Dalam penerapan Agrotech Farm System di Lahan Kelompok Tani Katon Jaya.

\section{b. Metode Kegiatan}

Metode Kegiatan ini diawali dengan diskusi dengan pihak Kelompok Tani Katon Jaya mengenai areal yang akan digunakan untuk Integrasi Agrotech Farm System. Setelah didapatkan posisi lahan. Tim Pengabdian kemudian menyusun Prosedur Pengerjaan Lahan dan Pemasangan Agrotech Farm System di Kelompok Tani Katon Jaya Kelurahan Agrowisata Kecamatan Rumbai Kota Pekanbaru. Jadwal pengelolaan lahan serta pemasangan diatur agar sesuai dengan waktu yang telah ditentukan. Mulai dari pembedengan tanah, penanaman mulsa tanaman, penanaman binih bibit(Huda, Harisuseno, and Priyantoro 2012). Kemudian dilanjutkan pemasangan Alat Agrotech Farm system dengan memanfaatkan pipa paralon untuk mengalirkan air dan pupuk yang berasal dari tanki mereka masing-masing. Instalasi itu dikerjakan bersamaan dengan pemasangan mesin air guna. Setelah semua komponen terpasang dilakukan pengujian apakah alat berfungsi dengan baik (Nawandar and Satpute 2019)(Canales-ide, Zubelzu, and Rodríguezsinobas 2019).

Setelah Metode pertama selesai dikerjakan selanjutnya dilanjutkan dengan pemberian pengetahuan mekanisme Alat kepada Kelompok Tani Katon Jaya. Mereka diterjunkan langsung untuk penggunaan dari Agro Tech Farm System. Metode praktek, diskusi, tanya jawab serta pendampingan terus dilakukan agar Kelompok Tani Katon Jaya memahami dengan sepenuhnya mekanisasi dari penggunaan Agro Tech Farm System. Pendampingan terus dilakukan dan Tim Pengabdian akan melihat tingkat keberhasilan dari penggunaan Agro Tech Farm System ini pada Kelompok Tani Katon Jaya Kelurahan Agrowisata Kecamatan Rumbai Kota Pekanbaru.

\section{c. Langkah Pelaksanaan}

Pada Penelitian sebelumnya (Nasution et al. 2019) Tim Pengabdian telah berhasil mengembangkan Agrotech Farm System. Agrotech Farm System adalah Sistem pengendali dari irigasi tanaman. Software ini menggunakan platform web based. Interface aplikasi ini bisa diakses melalui layanan web. Hardware dan Software yang digunakan sudah berhasil Tim Pengabdian di kembangkan pada penelitian sebelumnya sebagai solusi dalam Otomatisasi Pertanian. Tim Pengabdian juga mengembangkan produk ini sebagai upaya membantu petani dalam irigasi tanaman yang bisa dikendalikan secara otomatis melalui sistem yang ada (Barkunan, Bhanumathi, and Sethuram 2019; Tararani et al. 2018). Penelitian sebelumnya kami berhasil mengimplementasikannya pada beberapa jenis tanaman seperti cabe dan tanaman selada. 

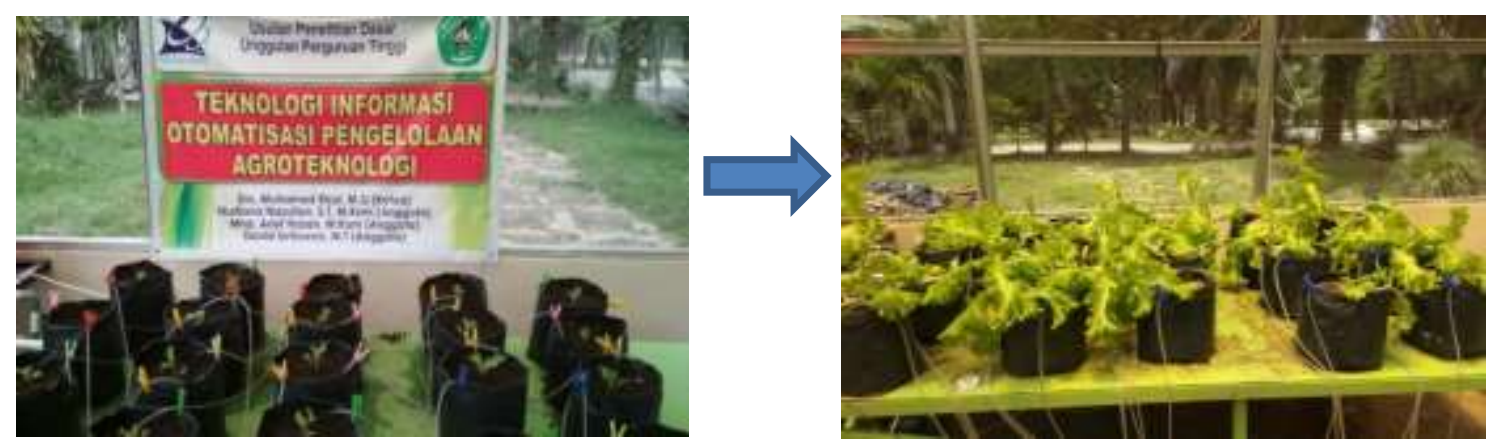

Gambar 5. Implementasi Agrotech Farm System pada Tanaman Selada
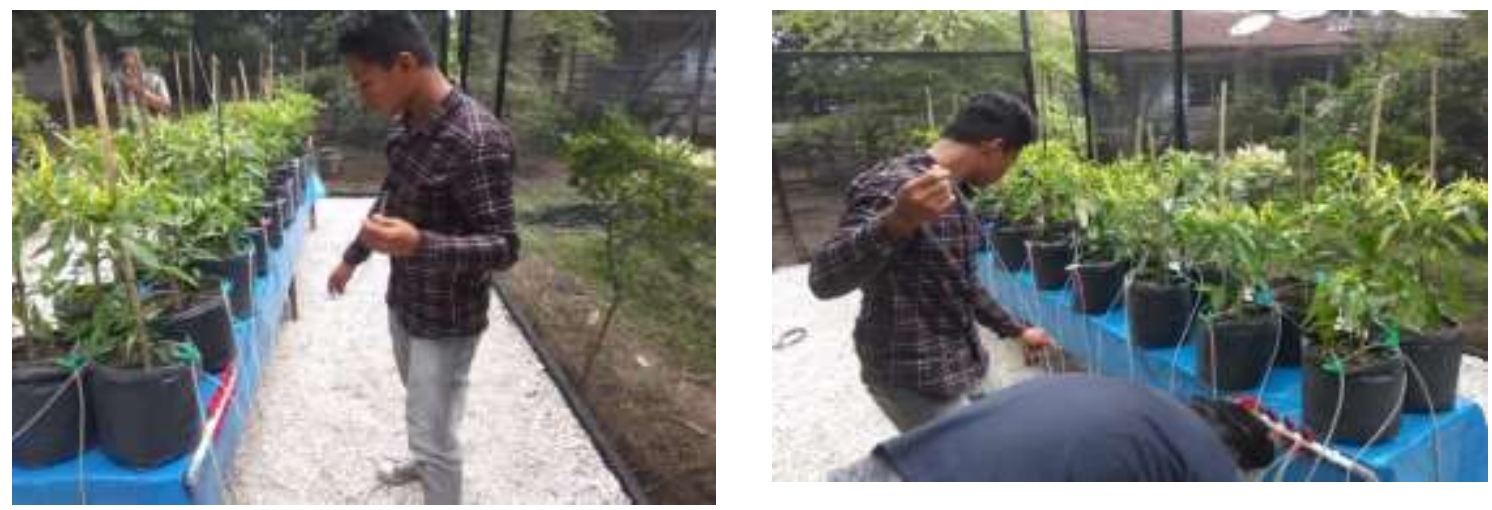

Gambar 6. Implementasi Agrotech Farm System pada Tanaman Cabe

Aplikasi ini dapat membantu petani dalam otomatisasi pada Teknologi Pertani. Sistem ini dibagun untuk mengendalikan penyiraman dan pemupukan secara otomatis dengan sensor kelembapan berbasis mikrokonroler ATmega 8535(Patel et al. 2014; Usha Rani and Kamalesh 2014). Beberapa komponen elektronika di sematkan pada perangkat ini untuk mengatur jadwal dari Pengairan dan Pemupukan Tanaman (Munir, Bajwa, and Cheema 2019)(Cambra et al. 2017). Berikut dari mekanisme kinerja penggunaan alat yang dapat dilihat pada Gambar 8.
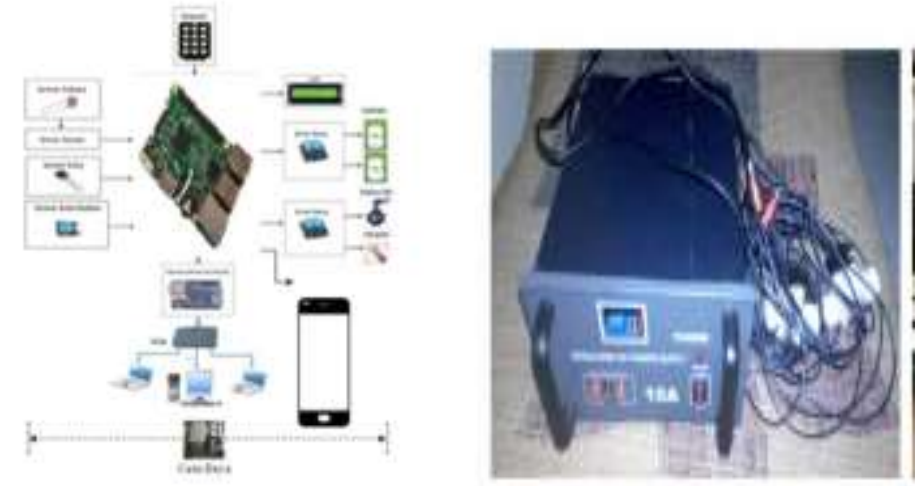

Gambar 7. Agrotech Farm System

Agrotech Farm System pada Gambar 8. merupakan kombinasi microcontroller Arduino atau Raspberry yang digunakan untuk kontrol tanaman. Beberapa sensor ini digunakan untuk mendapatkan data berupa suhu dan kelembapan dari tanaman. Microcontroller berfungsi untuk menghidupkan beberapa katub yang terkoneksi dengan air dan pupuk. Sehingga bisa diatur untuk penjadwalan air dan pupuk dari tanaman. Perangkat ini juga bisa dikontrol melalui aplikasi sehingga bisa datur jadwal penyiraman dan pemupukan serta log data.

Berikut langkah-langkah pelaksanaan Pengabdian Kepada Masyarakat ini di Kelompok Tani Katon Jaya Kelurahan Agrowisata Kota Pekanbaru Provinsi Riau. 
1. Pengabdian dilakukan dengan tiga tahapan, di mana tahap pertama merupakan tahap persiapan. Pada tahap ini kelompok pengabdi melakukan suvey pendahuluan untuk melihat kondisi di lapangan mengenai lahan dari Kelompok Tani Katon Jaya yang terbengkalai. Dalam tahap ini tim pengabdi akan melakukan pemetaan seberapa luas wilayah yang akan diimplementasikan Agro Tech Farm System.

2. Tahap selanjutnya merupakan tahapan pelaksanaan kegiatan pengabdian. Yakni dengan memberikan bantuan berupa budi daya tanaman sayur yang diintegrasikan dengan alat Agrotech Farm System.

3. Tahap Selanjutnya adalah melakukan sosialisasi penggunaan Agrotech Farm System ini kepada Seluruh Kelompok Tani Katon Jaya.

4. Tahap yang terakhir adalah tahap evaluasi antara hasil tanaman yang diperoleh dengan Penggunaan Agrotech Farm System. Pada tahap ini dilakukan evaluasi atas hasil yang telah dicapai oleh peserta pelatihan. Masukan dan perbaikan lebih lanjut dapat dilakukan pada tahap ini. Evaluasi diberikan dengan mengumpulkan data yang diperoleh dari kegiatan pelatihan pengembangan karya profesi. Data diambil dengan menyimpulkan hasil uji dilapangan dengan uji yang dilakukan sebelumnya yang telah dilakukan melalui penelitian.

Indikator ketercapaian tujuan pengabdian adalah bahwa 80\% Anggota Kelompok Tani Katon Jaya Memahami penggunaan Agrotech Farm System yang ada. Sehingga laboratorium mereka kembali dapat hidup sebagai media pembelajaran oleh pihak-pihak terkait yang ingin sepenuhnya belar dan memamahi budi daya tanaman berbasis teknologi otomatisasi pertanian.

\section{HASIL DAN PEMBAHASAN}

\subsection{Persiapan Kegiatan}

Langkah awal dari kegiatan pengabdian masyarakat ini yakni tim pengabdian dan mitra bersama-sama berdiskusi untuk melakukan pra kegiatan. Pra kegiatan ini dilakukan untuk membuat jadwal kegiatan agar terjadwal dengan baik. Adapun pra kegiatan itu adalah sebagai berikut :

\subsubsection{Persiapan Alat Agrotech Farm System}

Tim Pengabdian bersama praktisi di awal kegiatan menyiapkan alat Agrotech Farm System. Alat yang dibuat merupakan penyempurnaan dari model yang telah Tim Pengabdian kembangkan sebelumnya. Dimana komponen utama dari sistem ini menggunakan raspberry pi model 3. Raspberry pi merupakan komputer mini yang gampang untuk di program dan digunakan karena sudah ada sistem operasinya, Alat yang seukuran kartu kredit yang mudah diprogram dan digunakan karena sudah ada banyak fitur di dalamnya seperti wifi, bluetooh, Ethernet Card, Hdmi, Port Usb dan Audio. Dibekali sistem operasi dan mudah diprogram dengan menggunakan bahasa pemrograman python. Meskipun ukurannya kecil, raspberry cukup memiliki daya yang cukup untuk menjalankan beberapa aplikasi sekaligus sama seperti di komputer, mulai dari aplikasi pengolah office sampai games.

Beberapa komponen lain yang ada di Agro Tech Farm System ini antara lain PLC Modul, MCB, Pulse, Bus Bar, Contactor, Pus Button Manual, PLC, Relay, Power Supply. Semua komponen ini di rakit dalam box unit. Masing-masing komponen ini dirakit dan diprogram untuk menghidupkan katup air. Ada dua katup yang digunakan dalam pengabdian ini, yaitu untuk katup air dan katup pupuk. 

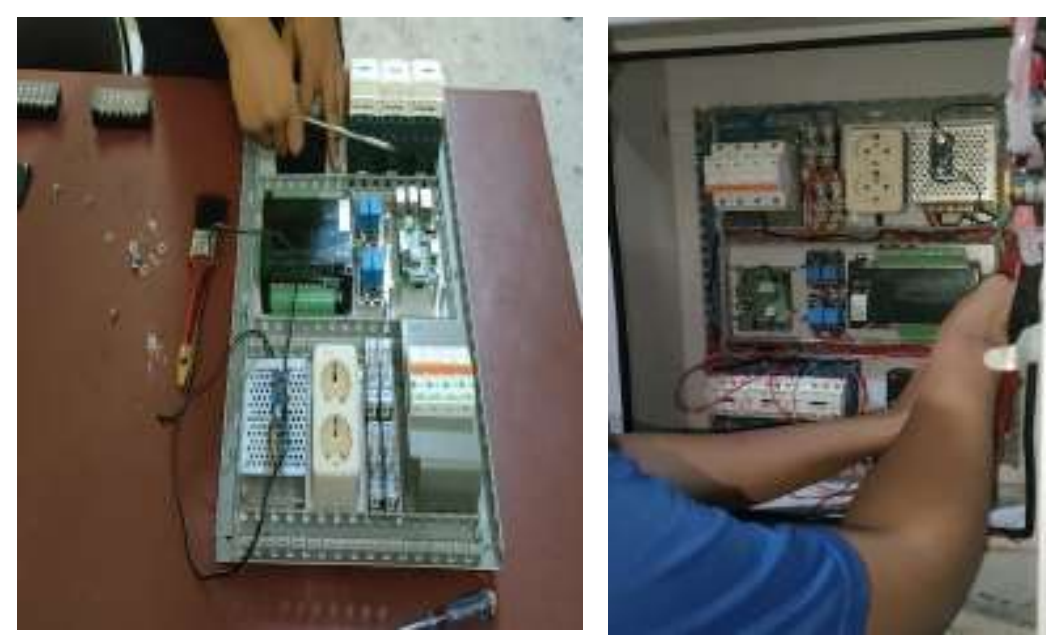

Gambar 8. Perakitan Agrotech Farm System

Pada gambar 8 dijelaskan bagaimana proses perakitan Agrotech Farm System. Semua Komponen di rakit dalam Unit Panel. Semua komponen sudah diuji dan terkoneksi dengan baik.

\subsection{Persiapan Lahan Pertanian}

Selain pengejaan unit, Tim Pengabdian bersama Kelompok Tani Katon Jaya juga berkoordinasi dengan baik dalam persiapan lahan untuk pelaksanaan Pengabdian Kepada Masyarakat ini. Lahan yang disiapkan ini merupakan lahan dari kelompok tani Katon Jaya yang bertempat di jalan Sri Kurnia Kelurahan Agrowisata Kecamatan Rumbai Barat Kota Pekanbaru. Lahan yang digunakan sebesar 40 x 40 Meter bidang tanah. Lahan ini dahulunya juga merupakan bagian dari laboratorium pertanian milik Kelompok Tani Katon Jaya sebelum mereka mengelola lahan milik Pemda Kota Pekanbaru yang berada di kawasan Agro.

Berikut ini merupakan persiapan-persiapan lahan yang dilakukan sebelum implementasi Agrotech Farm System di Kelompok Tani Katon Jaya Kelurahan Agrowisata Pekanbaru.

1. Permbersihan Lahan Milik Kelompok Tani Katon Jaya

Mengingat sebelumnya lahan milik Kelompok Tani Katon Jaya ini dalam keaadaan terbengkalai dan dipenuhi semak belukar. Maka tahap pertama yang dilakukan adalah pembersihan lahan. Pembersihan lahan dilakukan menggunakan mesin pemotong untuk memotong semak belukar yang telah tumbuh pada lahan milik Kelompok Tani Katon Jaya.
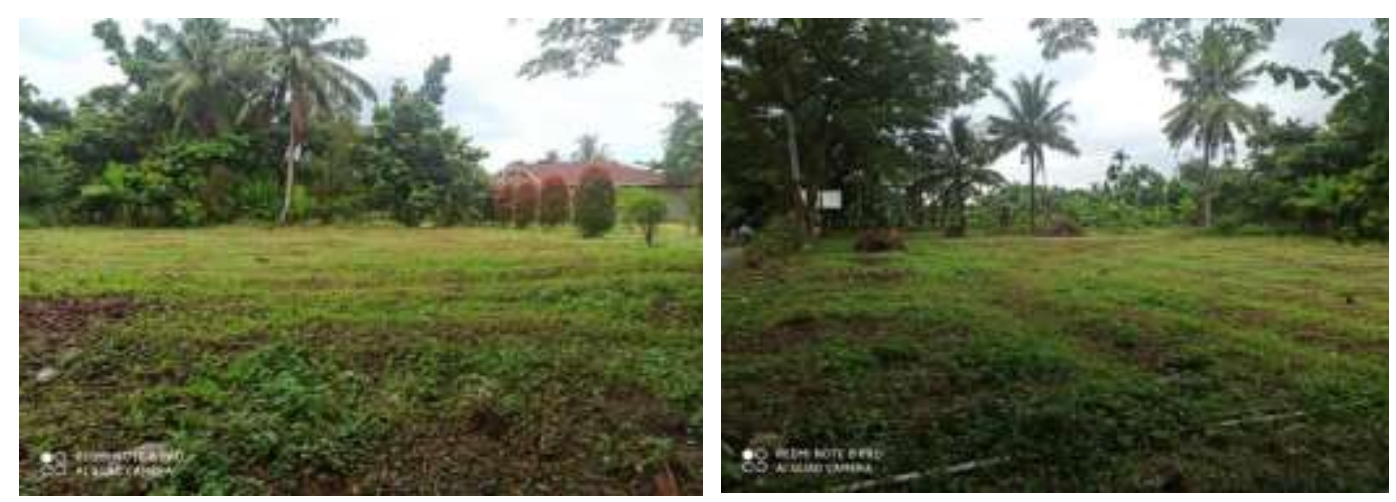

Gambar 9. Lahan Kelompok Tani Katon Jaya yang sudah bersih

\section{Permbajakan Lahan Tanam}

Setelah lahan dibersihkan kemudian lahan tersebut dilakukan pembajakan. Pembajakan dilakukan guna menggemburkan tanah dan menghilangkan sisa rumput yang ada pasca 
pembersihan lahan. Pembersihan lahan dilakukan menggunakan Jonder yang merupakan bantuan Pemerintah Kepada Kelompok Tani Katon Jaya.
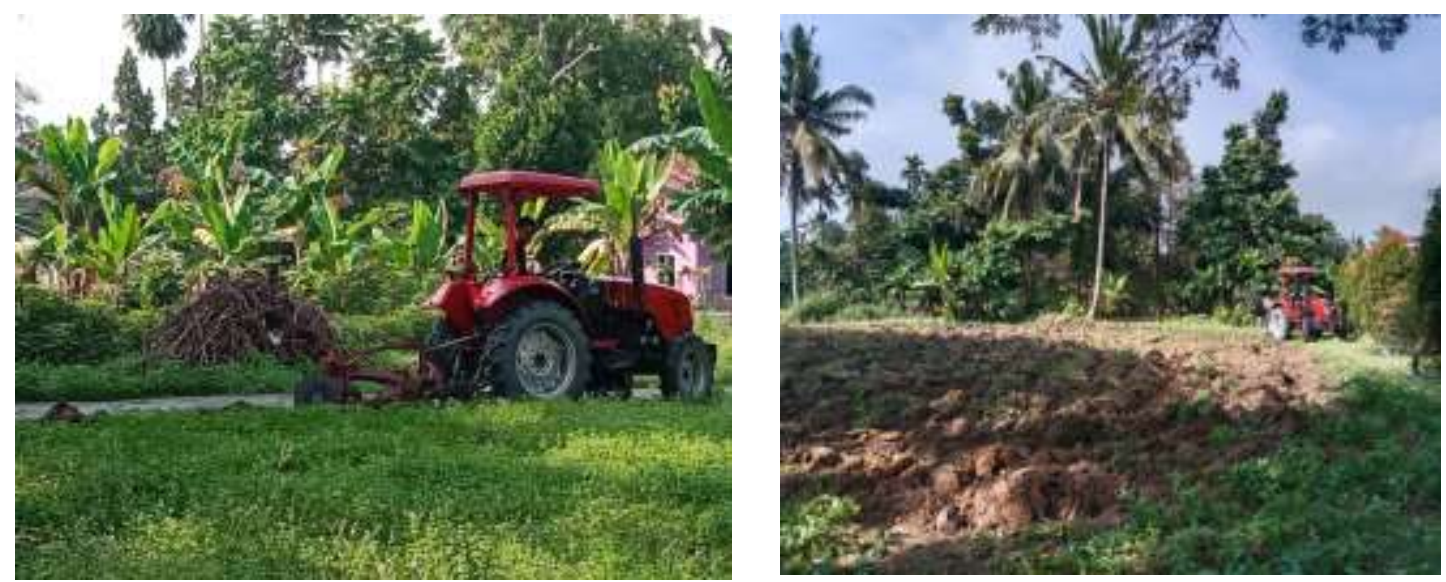

Gambar 10. Pembajakan Lahan

3. Penataan Lahan dan Desain Lahan Tanaman

Pada Tahap berikutnya setelah lahan berhasil di bajak menggunakan traktor, Tim Pengabdian bersama Kelompok Tani mulai membahas mengenai komoditas budidaya tanaman yang akan ditanam. Pada proses ini juga didiskusikan mengenai pemetaan lahan dan jadwal penanaman tanaman. Lahan ini di tata dengan baik agar nantinya bisa menjadi objek wisata pertanian berbasiskan teknologi.
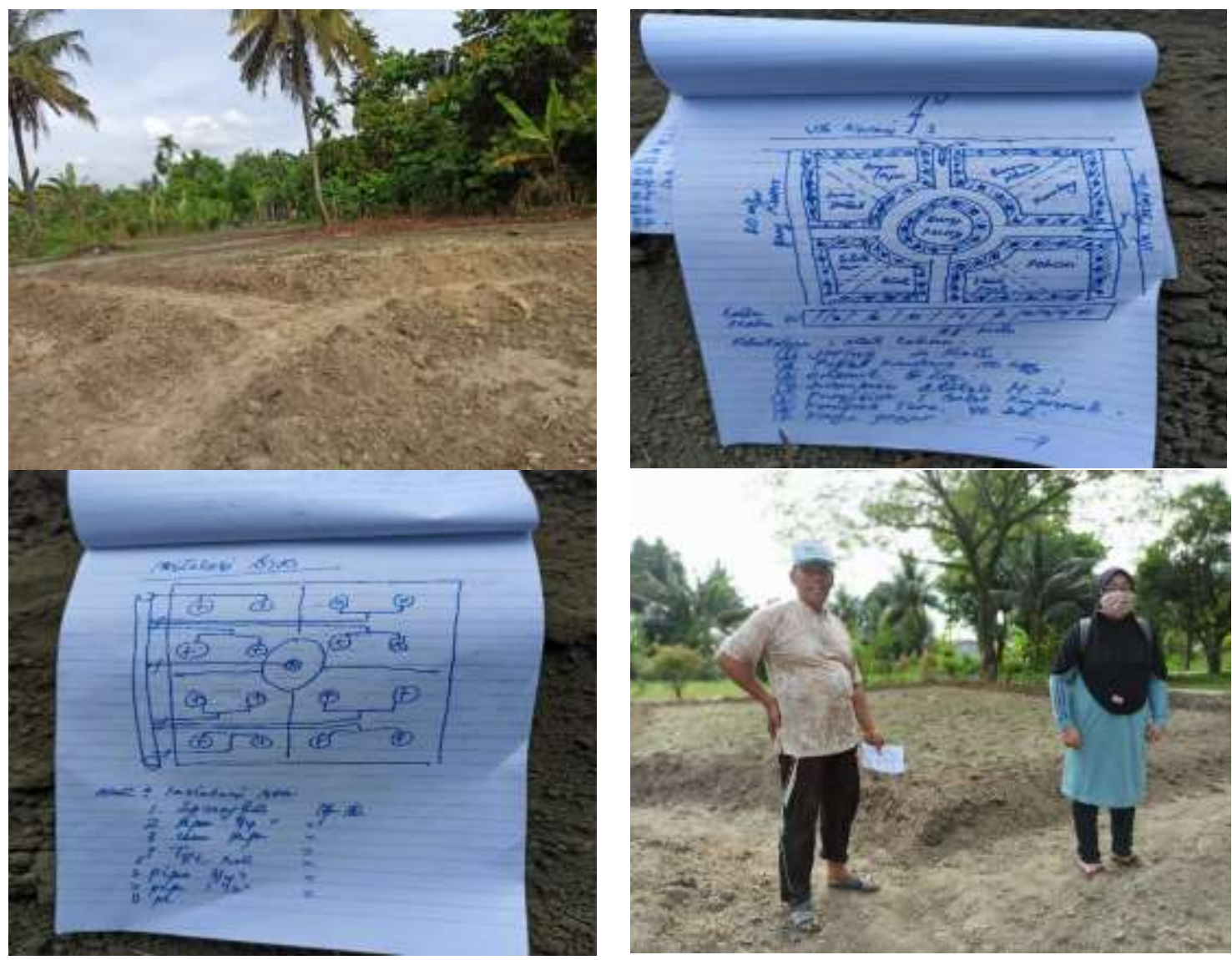

Gambar 11. Penataan dan Desain Lahan Tanaman

4. Pemberian Pupuk Dasar

Setelah Lahan di desain dan ditentukan tanaman yang akan di tanam. Maka masuk ke proses pemasukan Pupuk Dasar. Pemupukan Dasar ini ditujukan untuk memberikan kesuburan 
pada areal tanaman yang akan ditanam. Pupuk Dasar tersebut diantaranya Dolomyte, NPK, Pupuk Kandang dan lainnya. Pupuk Dasar ini di aduk dengan lahan tanaman dan dibiarkan selama 2 minggu agar Micro Organisme bisa berkembang dengan baik pada lahan tanaman.
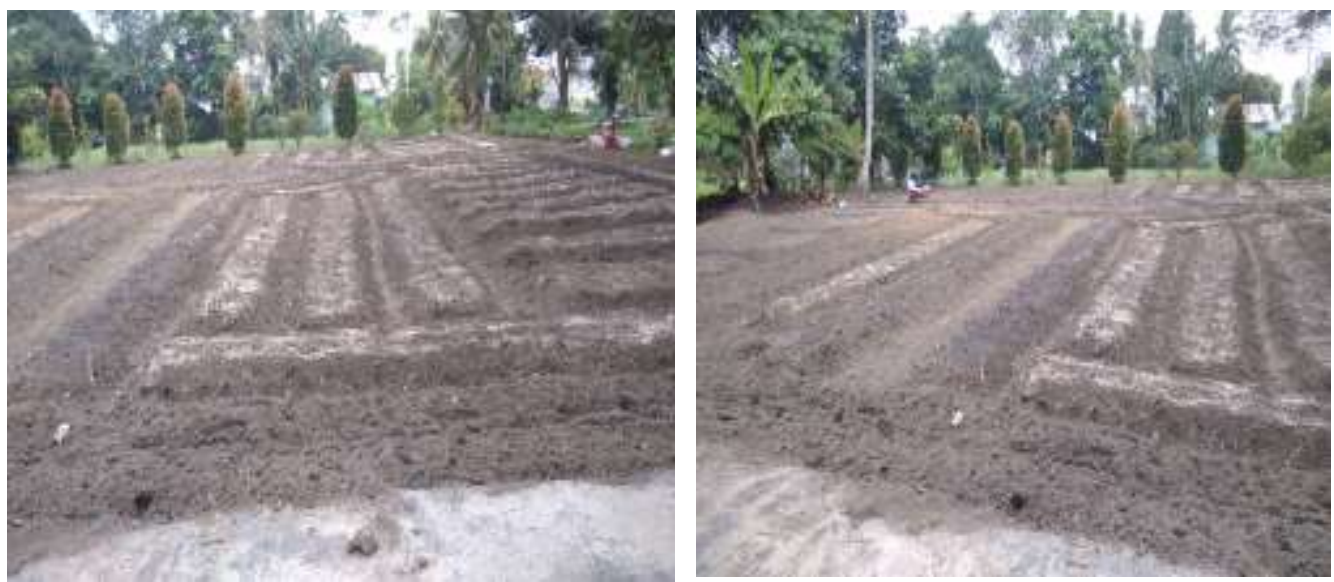

Gambar 12. Pemberian Pupuk Dasar

5. Pemasangan Jaring Pembatas

Setelah Lahan diberikan Pupuk kemudian lahan tersebut diberikan Jaring Pembatas. Hal ini ditujukan agar ketika bibit tanaman sudah masuk ke dalam media tanaman terhindar dari hama pengganggu seperti hewan ternak dan hama lainnya yang dapat merusak tanaman.

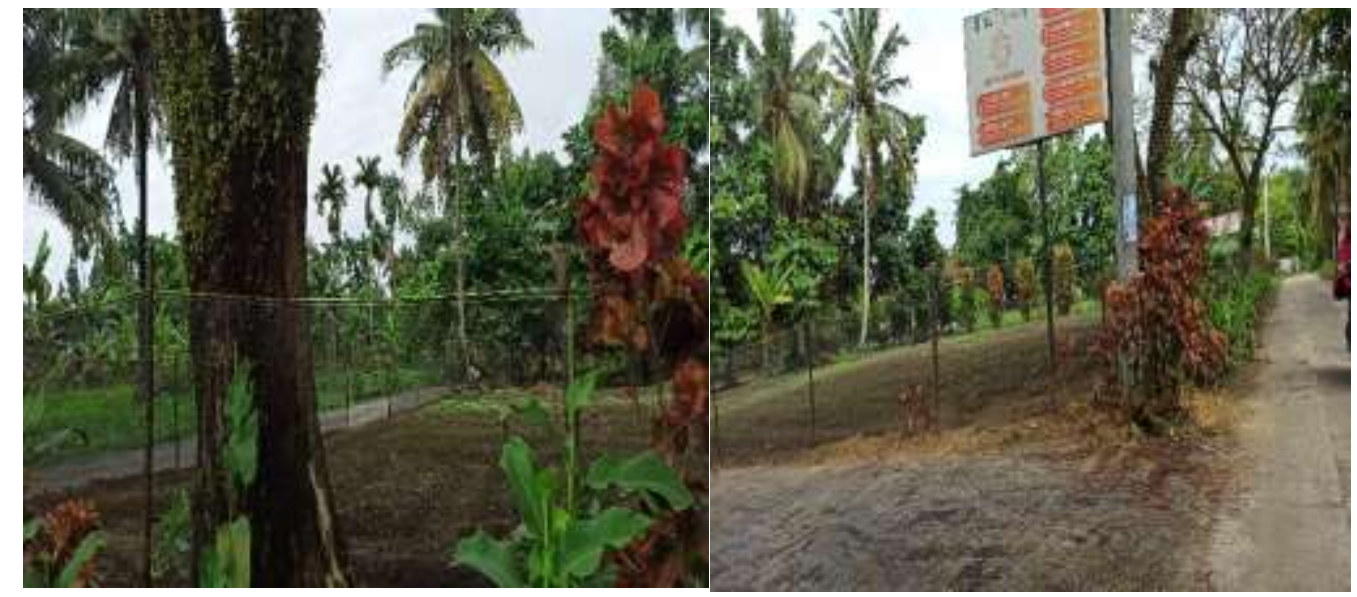

Gambar 13. Pemasangan Jaring Pembatas

\subsection{Implementasi Agrotech Farm System}

Pengabdian Kepada Masyarakat ini telah berhasil merubah lahan tidur milik kelompok tani Katon Jaya Kelurahan Agrowisata Kecamatan Rumbai Barat Kota Pekanbaru. Menjadi lahan produktif berbasis teknologi Informasi. Pada Awal sebelumya lahan ini dibiarkan terbengkalai. Dikarenakan anggota kelompok tani Katon Jaya telah sibuk mengolah lahan Agrowisata dari PEMDA Kota Pekanbaru. Adapun kondisi lahan sebelum diolah menjadi lahan produktif bisa dilihat pada gambar 14 . 

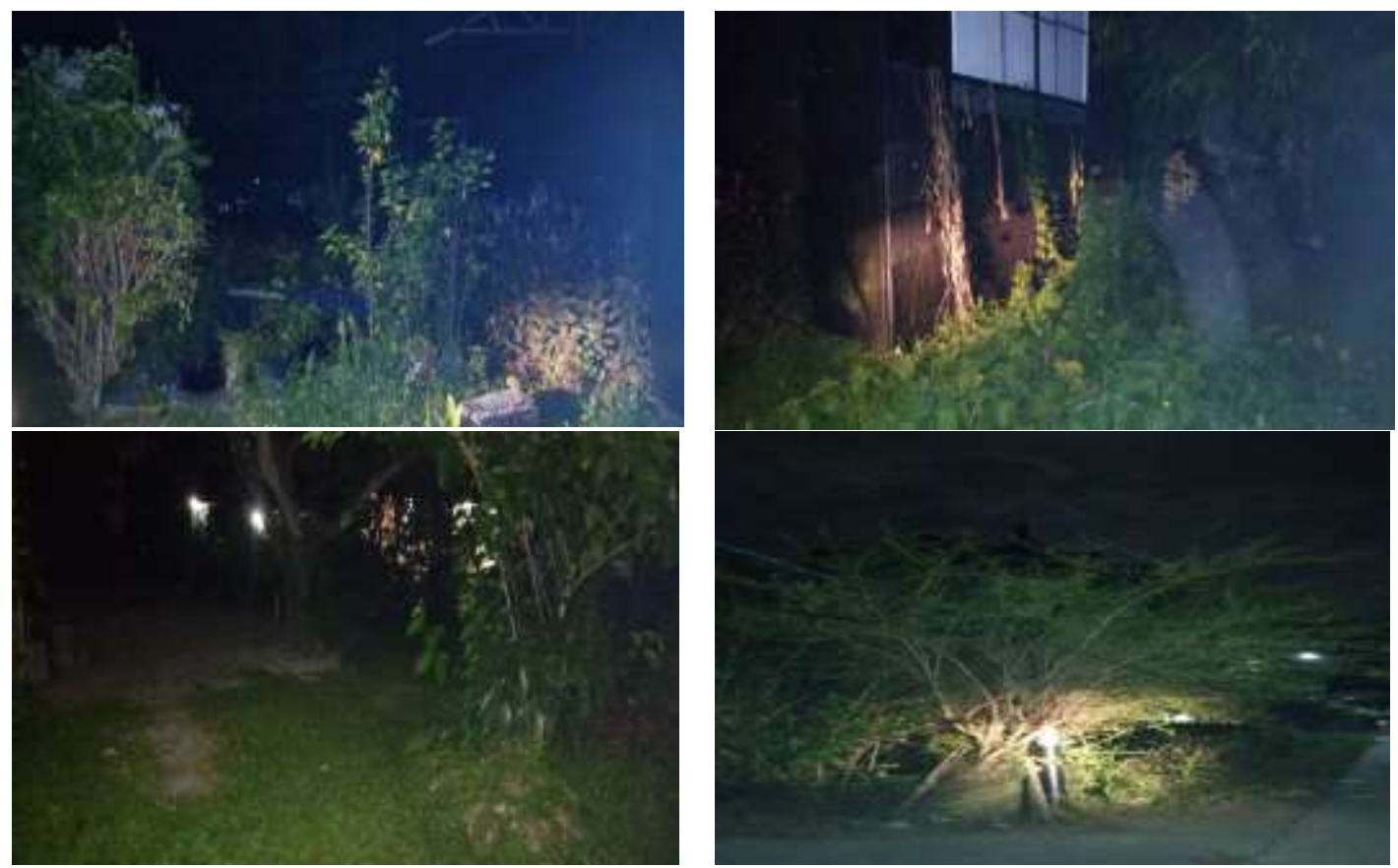

Gambar 14. Kondisi Lahan Sebelum Pengabdian Masyarakat

Gambar 14 menjelaskan kondisi lahan pertanian Kelompok Tani Katon Jaya yang ditumbuhi semak belukar saat ini. Pada foto terakhir dijelaskan bahwa daerah tersebut sudah dimasuki Indihome yang memungkinkan untuk dilakukan Pertanian Modern Berbasis Smart Teknologi.

Tim Pengabdian Masyarakat bekerjasama dengan Kelompok Tani Katon Jaya telah berhasil mengolah lahan terbengkalai, kemudian menanaminya dengan tanaman holtikultura, dan memasang alat Agro Tech Farm System. Seiring akan kebutuhan dari Kelompok Tani Katon Jaya akan otomatisasi dalam Teknologi Pertanian. Untuk membantu mereka dalam kemudahan penyiraman dan pemupukan yang otomatis di lahan produktif milik mereka sendiri.
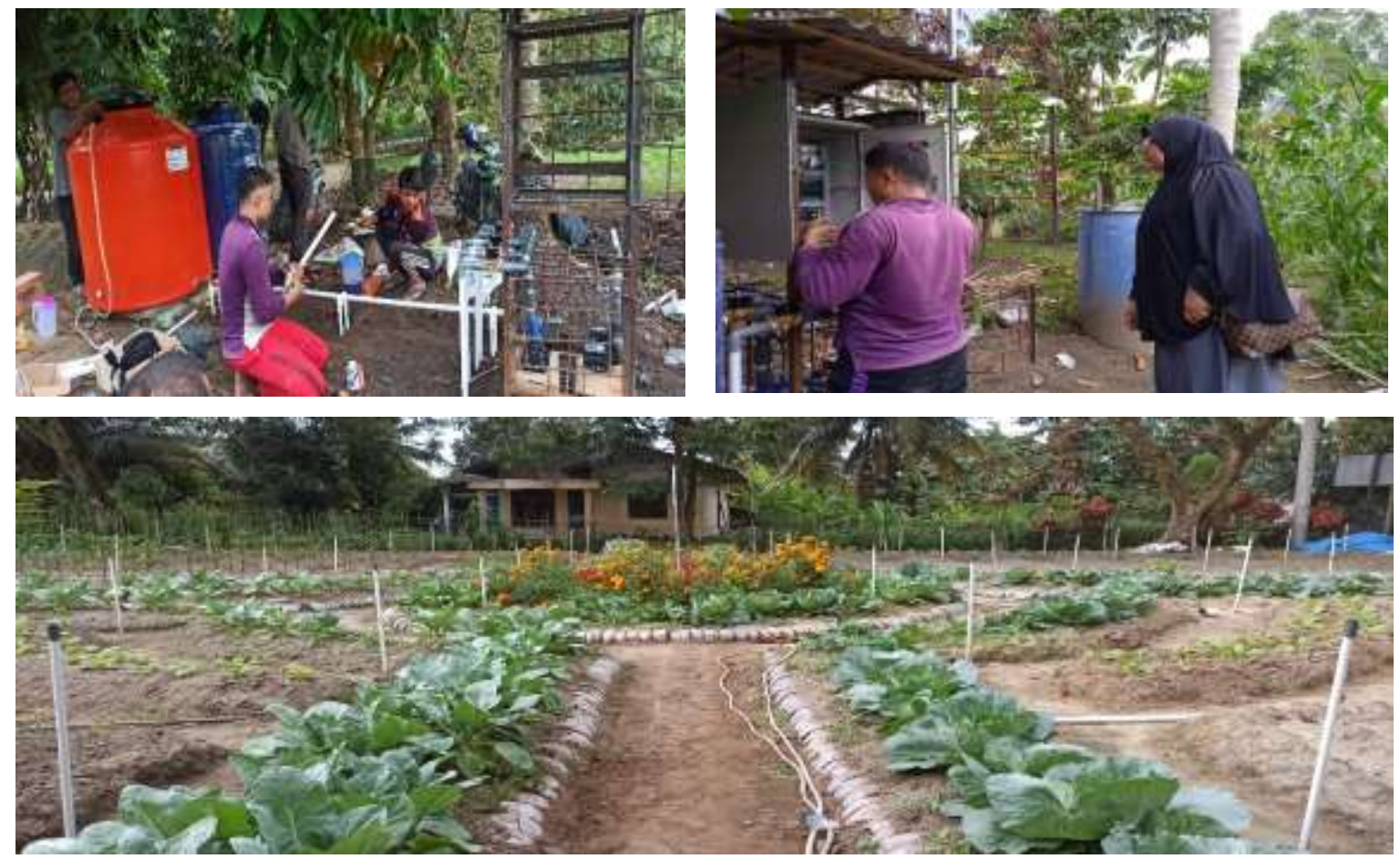

Gambar 15. Pemasangan Agrotech Farm System di Lahan Kelompok Tani Katon Jaya 
Gambar 15 diatas terlihat sudah di pasang alat Agrotech Farm System di Lahan Kelompok Tani Katon Jaya. Tampak pada gambar tersebut dimulainya dari pemasangan tandon air dan pupuk, listrik, mesin air, pipa drip penyiraman, dan Agrotech Farm.

Lahan Pertanian Kelompok Tani Katon Jaya sudah berubah wujud menjadi Labor Pertanian Berbasis Teknologi Informasi. Labor ini kedepan tentunya akan menjadi pusat studi Teknologi Informasi Berbasis Pertanian. Sebagai upaya menjawab dari tantangan Program Kerja Pemerintah Kota Pekanbaru yakni menjadikan Kota Pekanbaru Smart City Madani. Lahan ini dapat ditanam dengan beberapa tanaman holtikultura sebagai produk hasil pertanian.

Alat Agrotech Farm System ini sudah berhasil sepenuhnya membantu Kelompok Tani Katon Jaya. Dengan alat Agrotech Farm System para petani tidak perlu direpotkan lagi dengan penyiraman dan pemupukan. Karena pemupukan sudah dilakukan melalui sistem yang telah diterapkan melalui Agrotech Farm System ini. Hasil dari pengabdian masyarakat ini juga telah membuahkan hasil panen bermacam-macam sayuran dari tanaman pangan Laboratorium Agrotech Farm System di kelurahan Agrowisata Kecamatan Rumbai Kota Pekanbaru.
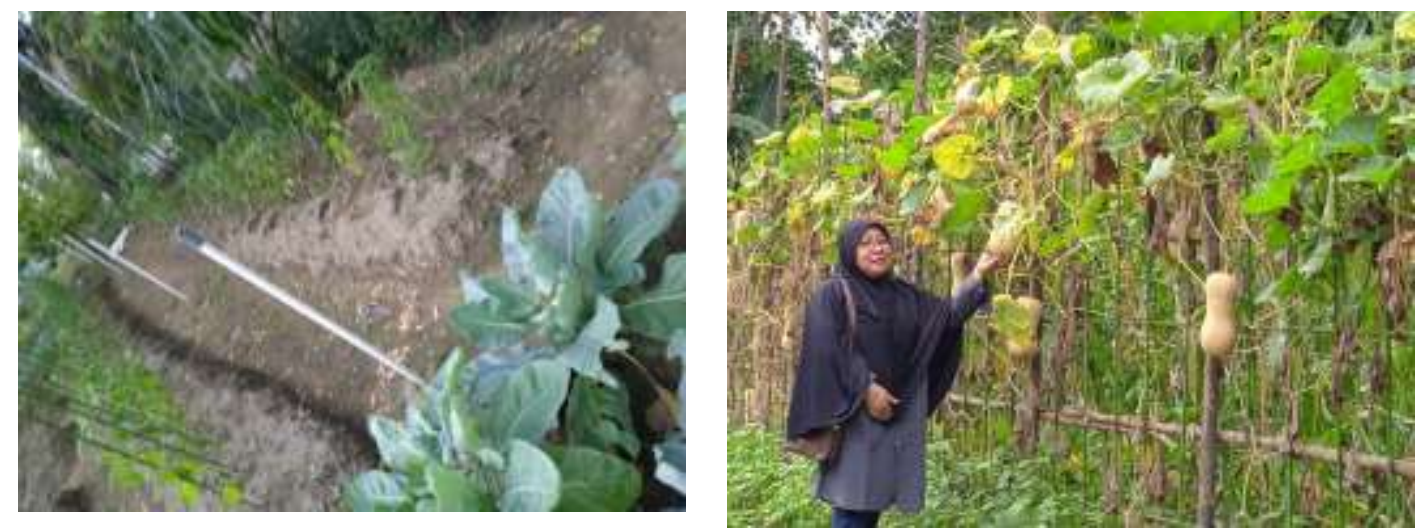

Gambar 16. Hasil Panen di Lahan Kelompok Tani Katon Jaya.

\section{KESIMPULAN}

Secara keseluruhan kegiatan Pengabdian Kepada Masyarakat ini telah terlaksana dengan baik. Mitra yakni Kelompok Tani Katon Jaya Kelurahan Agrowisata Kecamatan Rumbai Barat Kota Pekanbaru telah terbantu dengan menghidupkan kembali lahan mereka yang terbengkalai. Lahan Kelompok Tani Katon Jaya disulap menjadi lahan pertanian berbasis Teknologi Informasi dengan menggunakan otomatisasi dalam pertanian yang membuat nilai tambah dari kegiatan ini. Selain itu penerapan Agrotech Farm System ini juga bermanfaat terhadap keilmuan teknologi informasi dalam pertanian. Dikarenakan lahan pertanian ini dapat menjadi pusat studi kunjungan dari stakeholder yang ingin belajar pertanian berbasis teknologi informasi. Serta menjawab tantangan dari visi misi PEMDA Kota Pekanbaru yakni menjadikan Kota Pekanbaru Smart City Madani dengan salah satunya penerapan Smart Farming.

Penerapan alat Agrotech Farm System ini belumlah sepenuhnya sempurna. Masih perlu kajian mendalam, agar Agrotech Farm System bisa dioptimalkan lebih baik. Salah satunya mengenai besaran pengeluaran air dan pupuk berdasarkan kondisi umur tanaman, cuaca, suhu dan kelembapan. Kemudian alat ini juga belum dilengkapi dengan penanganan hama serta pengolahan pasca panen. Semua kendala ini menjadi saran untuk pengembangan alat Agrotech Farm System ini bisa dikembangkan lebih baik ke depannya. Agar terciptanya modernitas dalam pertanian yang lebih baik lagi. 


\section{UCAPAN TERIMA KASIH}

Kami Mengucapkan terima kasih yang sebesar-besarnya kepada Pemerintah Indonesia yang telah mendanai Pengabdian Kepada Masyarakat oleh RISTEKBRIN melalui Kontrak LPPM Universitas Lancang Kuning Nomor RISTEKBRIN dengan Nomor Kontrak LPPM UNILAK Nomor 206/LPPM/Pm/2021

\section{DAFTAR PUSTAKA}

Agrowisata, Kelurahan, and Di Kota. 2021. "PUBLIKA : Jurnal Ilmu Administrasi Publik Partisipasi Masyarakat Dalam Pengembangan Kepariwisataaan." 7(2): 214-26.

Barkunan, S R, V Bhanumathi, and J Sethuram. 2019. "Smart Sensor for Automatic Drip Irrigation System for Paddy Cultivation R." Computers and Electrical Engineering 73: 180-93. https://doi.org/10.1016/j.compeleceng.2018.11.013.

Cambra, Carlos, Sandra Sendra, Jaime Lloret, and Laura Garcia. 2017. "An IoT Service-Oriented System for Agriculture Monitoring." IEEE International Conference on Communications (May).

Canales-ide, Freddy, Sergio Zubelzu, and Leonor Rodríguez-sinobas. 2019. "Irrigation Systems in Smart Cities Coping with Water Scarcity : The Case Of." Journal of Environmental Management 247(December 2018): 187-95. https://doi.org/10.1016/j.jenvman.2019.06.062.

Huda, M Nurul, Donny Harisuseno, and Dwi Priyantoro. 2012. "Kajian Sistem Pemberian Air Irigasi Sebagai Dasar Penyusunan Jadwal Rotasi Pada Daerah Irigasi Tumpang Kabupaten Malang." Jurnal Teknik Pengairan 3(2): 221-29.

Munir, M Safdar, Imran Sarwar Bajwa, and Sehrish Munawar Cheema. 2019. "An Intelligent and Secure Smart Watering System Using Fuzzy Logic and Blockchain $九$." Computers and Electrical Engineering 77: 109-19. https://doi.org/10.1016/j.compeleceng.2019.05.006.

Nasution, Nurliana, Muhammad Rizal, David Setiawan, and Mhd Arief Hasan. 2019. "IoT Dalam Agrobisnis Studi Kasus: Tanaman Selada Dalam Green House." It Journal Research and Development 4(2): 86-93.

Nawandar, Neha K, and Vishal R Satpute. 2019. "IoT Based Low Cost and Intelligent Module for Smart Irrigation System." Computers and Electronics in Agriculture 162(December 2018): 979-90. https://doi.org/10.1016/j.compag.2019.05.027.

Patel, Nilesh R. et al. 2014. "Smart Design of Microcontroller Based Monitoring System for Agriculture." 2014 International Conference on Circuits, Power and Computing Technologies, ICCPCT 2014: 1710-13.

Siswati, Latifa, Dedi Zargustin, and Rini Nizar. 2020. "Pertanian Terpadu Sebagai Sumber Penapatan Di Kelurahan Agrowisata Di Kecamatan Rumbai Kota Pekanbaru." Jurnal Agribisnis 21(2): 135-41.

Tararani, Gaikwad et al. 2018. "Smart Drip Irrigation System Using IOT.” : 674-76.

Taufiq, Reny Medikawati, Sunanto Sunanto, and Yoze Rizki. 2020. "Integrated Smart Traffic Control System Menuju Pekanbaru Sebagai Smart City." JURTEKSI (Jurnal Teknologi dan Sistem Informasi) 7(1): 67-74.

Usha Rani, M., and S. Kamalesh. 2014. "Web Based Service to Monitor Automatic Irrigation System for the Agriculture Field Using Sensors." 2014 International Conference on Advances in Electrical Engineering, ICAEE 2014. 